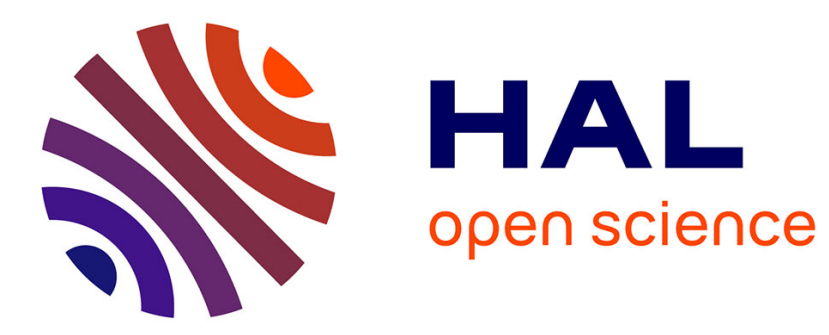

\title{
Thermo-mechanical modeling of plasterboard- lined partition submitted to fire load
}

\author{
S. Sakji, Christian Soize, J.-V. Heck
}

\section{To cite this version:}

S. Sakji, Christian Soize, J.-V. Heck. Thermo-mechanical modeling of plasterboard- lined partition submitted to fire load. 17th ACSE Analysis and Computation Speciality Conference, May 2006, St Louis, United States. pp.Pages 1-14. hal-00689692

\section{HAL Id: hal-00689692 https://hal.science/hal-00689692}

Submitted on 19 Apr 2012

HAL is a multi-disciplinary open access archive for the deposit and dissemination of scientific research documents, whether they are published or not. The documents may come from teaching and research institutions in France or abroad, or from public or private research centers.
L'archive ouverte pluridisciplinaire HAL, est destinée au dépôt et à la diffusion de documents scientifiques de niveau recherche, publiés ou non, émanant des établissements d'enseignement et de recherche français ou étrangers, des laboratoires publics ou privés. 


\title{
Thermo-mechanical modeling of plasterboard lined partition submitted to fire load.
}

\author{
Authors: \\ S. Sakji ${ }^{1,2}$, C. Soize ${ }^{2}$, J.V. Heck ${ }^{1}$ \\ ${ }^{1}$ Centre Scientifique et Technique du Bâtiment (CSTB), Paris, France. \\ ${ }^{2}$ Université de Marne-la-Vallée (UMLV), France. \\ seddik.sakji@cstb.fr, soize@univ-mlv.fr,jv.heck@cstb.fr
}

\begin{abstract}
:
An important problem is the development of a thermo-mechanical model of plasterboard lined partition submitted to fire load. A fundamental key to solve such a problem is the development and the experimental validation of a deterministic and a probabilistic thermo-mechanical model of cardboard-plaster-cardboard (CPC) submitted to fire load. The proposed model takes into account data and modeling uncertainties. This research is justified by the fact that fire resistance tests of plasterboard lined partition are made impossible when their dimensions exceed those of furnaces. This research is organized in four steps. The first one concerns the constitution of an experimental thermo-mechanical data base for a CPC multilayer and for its components. These experimental tests are carried out by the use of a bench test specially designed for this work. This device reproduces a heat flux equivalent to the one produced during a mandatory test using a gas furnace. The second step is the development of an homogenization thermomechanical mean model for the CPC multilayer. This mean model is adapted to a temperature range in which plaster or cardboard may be damaged. The third step is devoted to the implementation of the probabilistic model to take into account data and model uncertainties. In the last step, we present the results of numerical simulations which are compared to the experimental data.
\end{abstract}

\section{INTRODUCTION}

Large light partitions (10 meters and more) are unload bearing structures. They are made of plasterboards screwed on both sides of a metal frame of various constructive configurations. Besides structural requirements such as the resistance to impact loading and collision loads [1], a light partition must verify various fire resistance criteria such as the carrying out of full scale tests under the ISO 834 thermal loading curve [2]. This last requirement can not be met when the structure dimensions exceed those of the testing furnaces (up to $3 \mathrm{~m}$ ). One way to circumvent the dimensional difficulty consists in evaluating partition behavior by means of an experimental and numerical combined approach. Benouis [3] adopted this approach but only to asses the mechanical behavior of light partitions at room temperature. The fundamental key to solve the above problem is 
to develop and validate with experiments a deterministic and a probabilistic thermomechanical model of plasterboard submitted to fire load. Plasterboard, a cardboardplaster-cardboard (CPC) multilayer, gives a partition higher resistance thanks to the important quantity of capillary and chemically bound water contained in the plaster $(21 \%$ of its weight) [4]. The first step of our research deals with identifying the CPC mechanical characteristics under fire and mechanical loading. For that, one adopt a thermo-mechanical experimental approach taking implicitly into account the hydrous phase. Indeed, the mechanical characteristics of the CPC multilayer are determined under the same thermal loading that a partition would receive during conventional resistance tests. For this matter, a new thermal loading bench (TLB) is designed allowing a time evolution thermal load equivalent to the ISO834 function to be reproduced on CPC specimens and then one performs, quickly, mechanical tests. A thermo-mechanical mean model is developed using a homogenization in the thickness of the CPC. In this model, Najar's brittle damage model is introduced for the plaster. A devoted finite element code has been developed and takes into account the evolution of damage within the layers. This mean model is validated with experiments and constitutes a basis model to implement the nonparametric probabilistic model allowing uncertainties to be taken into account. Finally, the numerical results are compared to the experiments.

\section{EXPERIMENTAL IDENTIFICATION OF THE THERMOMECHANICAL PROPERTIES OF THE CPC}

To identify the thermo-mechanical properties of the CPC, a thermo-mechanical approach, taking implicitly into account the hydrous phase, is adopted. During ISO834 equivalent thermal loading, each CPC specimen is parallel to the heat source. Only one side of the specimen is exposed to the heat source. Consequently, the direction of the heat flux and the hydrous transport is mainly transversal to the specimen. The experimental approach is developed in two steps:

- Thermal loading by means of a thermal load bench (TLB) designed and put on for this work,

- Thermo-mechanical identification by means of a four points bending test.

\section{Thermal load bench (TLB)}

The TLB (Figure 1) reproduces an incidental heat flux equivalent to the one that a partition would receive during a mandatory test using a gas furnace. It is composed of a radiant panel (the heat source) and a mobile cart provided with a specimen holder. The heat flux received by the specimen, hang on the specimen holder, is modified by moving the cart with respect to the radiant panel. Hence, one can reproduce the ISO thermal load equivalent heat flux, not by modifying the flow of combustible gas ( as during tests on conventional furnaces), but by modifying the distance between the specimen and the radiant panel. The specimen thermal loading takes place only when the radiant panel reaches its steady state. Therefore the illumination can be considered as constant throughout the test duration. The combination of a heat source used in its steady state and a specimen movement controlled with a millimeter precision insures an excellent reproducibility on the thermal load. Furthermore the ECHAFO software [5] developed in order to model thermal exchanges in fire resistance furnaces, allows us to perform the 
calculation of the total heat flux received by the specimen surface at different time steps of conventional fire resistance test. First, one characterizes the incidental heat flux received by a fluxmeter at different distances from the radiant panel and then the cart displacement program is find out in order to reproduce by means of the TLB the incidental heat flux calculated by ECHAFO. Figure 2 compares the TLB proposed heat flux with the calculated incidental heat flux on the surface of a plasterboard specimen submitted to the ISO thermal load in a conventional furnace.

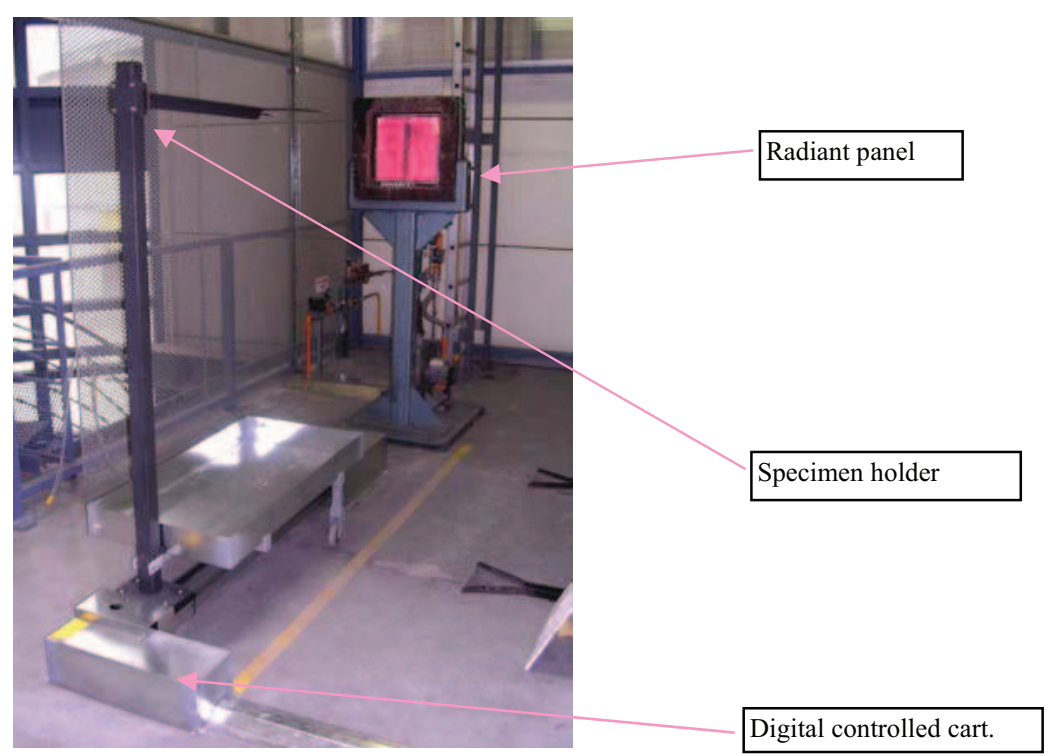

FIGURE 1

THERMAL LOAD BENCH

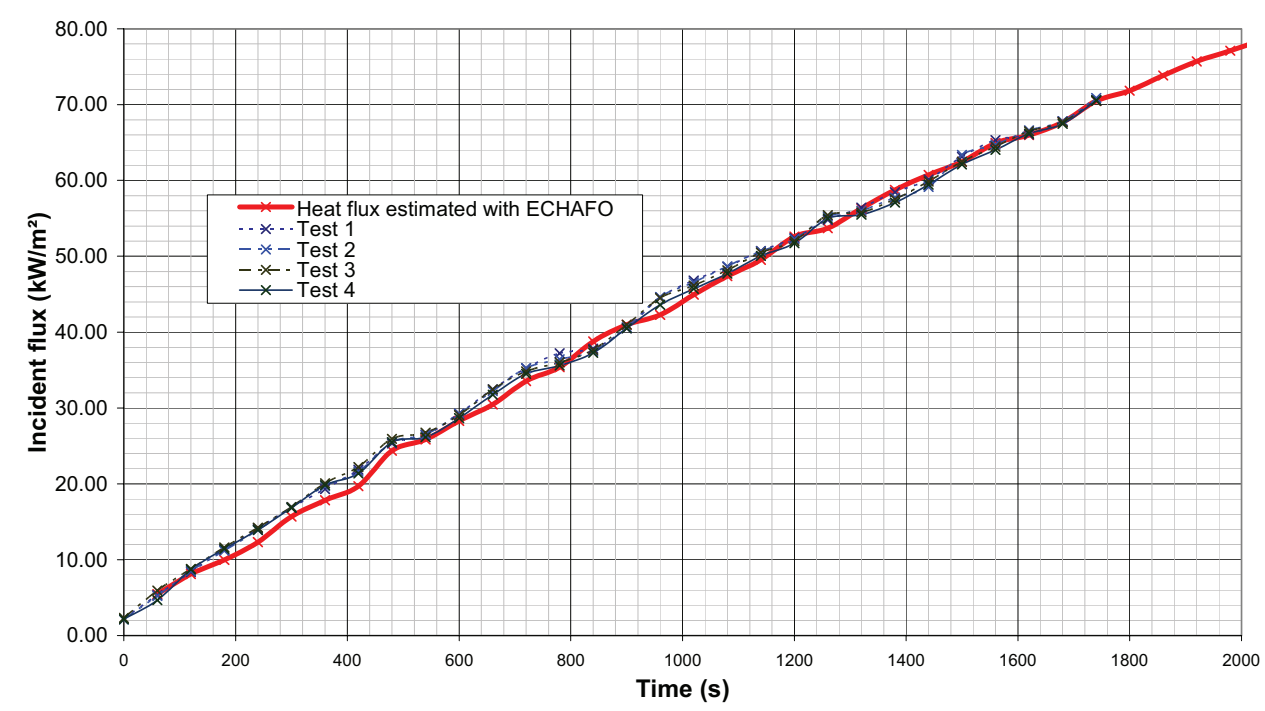

FIGURE 2

HEAT FLUX (VERTICAL AXIS IN KW/m²) AS A FUNCTION OF TIME (HORIZONTAL AXIS IN SECOND): CALCULATED HEAT FLUX (THICK SOLID LINE), TLB MEASURED HEAT FLUX (THIN LINES) 


\section{Mechanical load bench}

The second step of the experimental protocol concerns the thermo-mechanical identification tests of the CPC multilayer and its components. The Young modulus of the CPC multilayer corresponding to different time steps of the ISO thermal load has been identified. Therefore, after having exposed a $0.4 \times 0.4 \mathrm{~m}^{2}$ specimen to a time evolution of heat flux corresponding to the ISO thermal load using the TLB, a $0.08 \times 0.4 \mathrm{~m}^{2}$ specimen is cut in the specimen central part. A four points bending test is then performed quickly. The choice of the specimen dimensions (cutting out a $0.08 \times 0.4 \mathrm{~m}^{2}$ specimen in the thermal loaded specimen) is motivated by a concern to preserve hydrous boundary conditions in avoiding the steam loss in the specimen central part. Concerning cardboard, the same protocol is adopted, the bending test being replaced by a tensile test. These mechanical tests are achieved using an INSTRON press of 500 daN capacity and a $5.10^{-3}$ $\mathrm{m} /$ minute displacement rate.

\section{Thermo-mechanical experimental results}

As the plasterboard is an orthotropic material, the bending tests are carried out in the longitudinal (LL), transversal (TT), and diagonal (LT) directions at different steps of the time evolution ISO thermal loading (ambient temperature, 300s ISO, 420s ISO and 600s ISO). For each configuration (mechanical load direction/ thermal load time step), six specimens are tested. A measure of temperature is performed using a thermocouple located in the middle of plasterboard and gives a correspondence between the ISO loading time and the average temperature in the plasterboard.

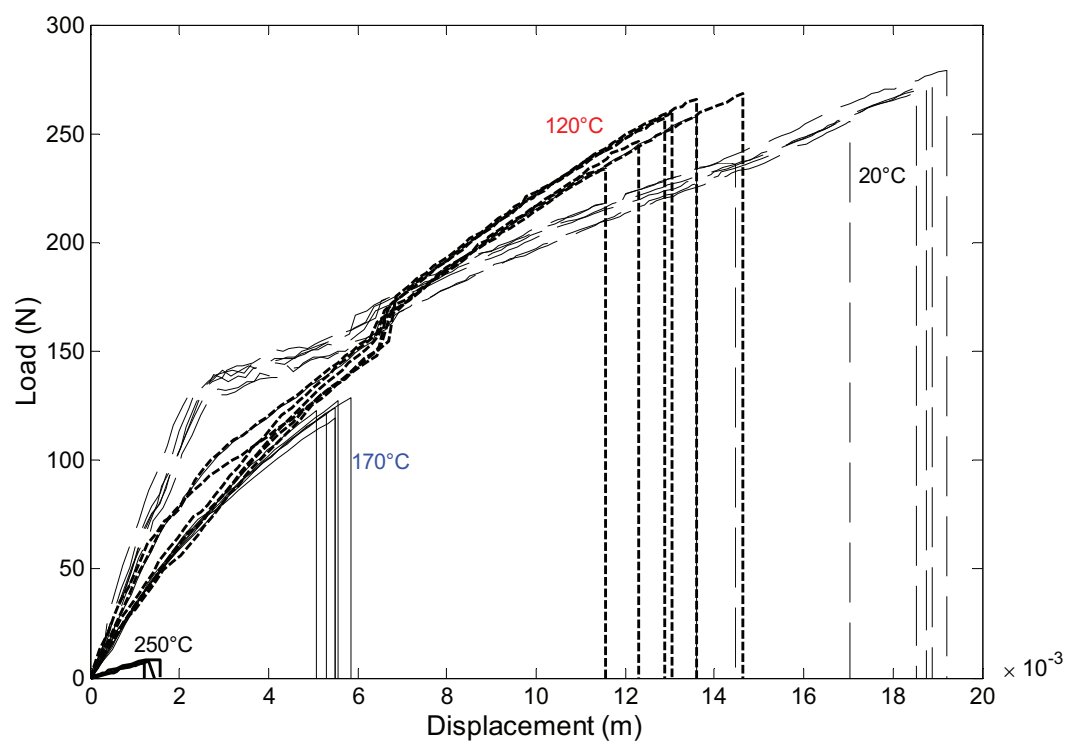

FIGURE 3

BENDING TEST EXPERIMENTS FOR DIFFERENT VALUE OF TEMPERATURE ON CPC SPECIMENS CARRIED OUT IN THE LONGITUDINAL DIRECTION: GRAPH OF THE MECHANICAL LOAD (VERTICAL AXIS IN N) AS A FUNCTION OF THE TRANSVERSAL DISPLACEMENT (HORIZONTAL AXIS IN METERS): THICK SOLID LINES $\left(250^{\circ} \mathrm{C}\right)$, THIN SOLID LINES $\left(170^{\circ} \mathrm{C}\right)$, THICK DASHED LINES $\left(120^{\circ} \mathrm{C}\right)$, THIN DASHED LINES $\left(20^{\circ} \mathrm{C}\right)$ 


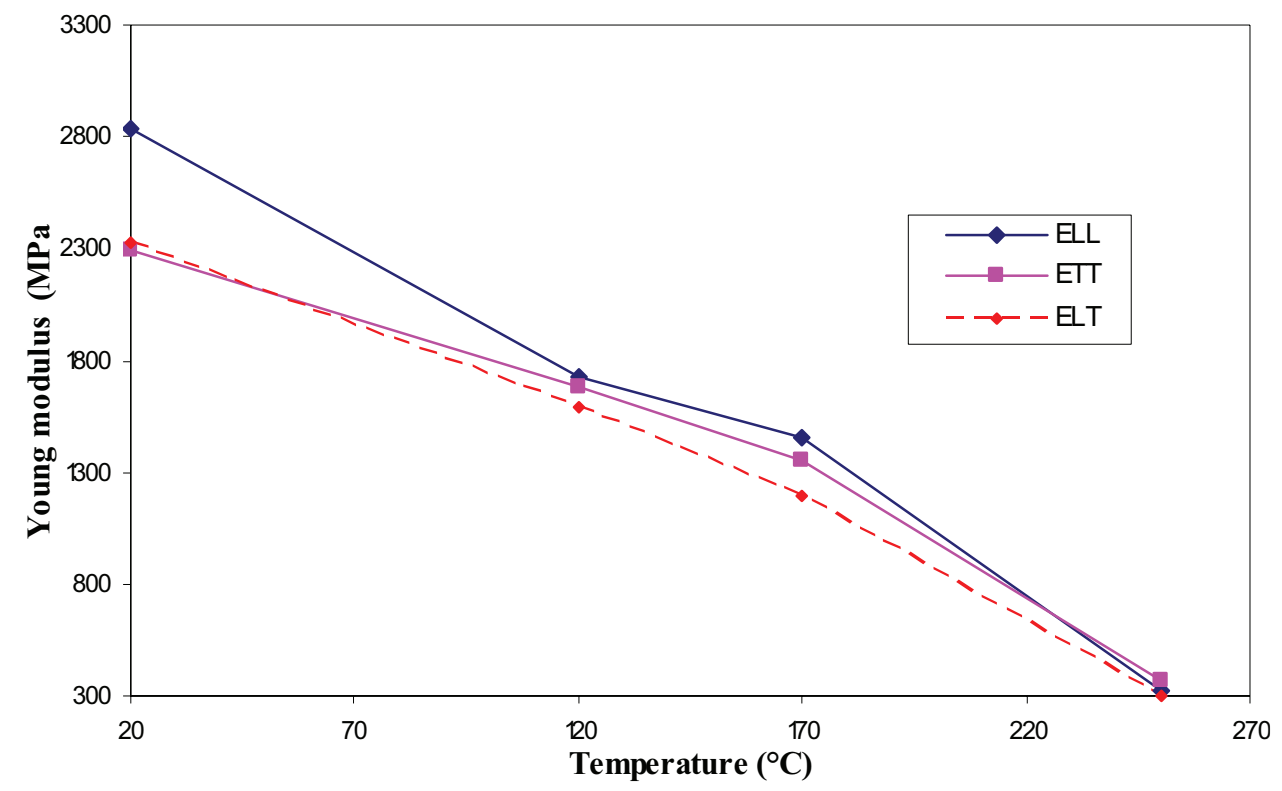

FIGURE 4

THERMOMECHANICAL EXPERIMENTS FOR THE CPC: GRAPH OF MEAN YOUNG'S MODULUS (VERTICAL AXIS IN MPA) AS A FUNCTION OF THE AVERAGE TEMPERATURE IN THE CPC (HORIZONTAL AXIS IN ${ }^{\circ} \mathrm{C}$ ): THICK SOLID LINE $\left(\mathrm{E}_{\mathrm{LL}}\right)$, THIN SOLID LINE $\left(\mathrm{E}_{\mathrm{TT}}\right)$, DASHED LINE $\left(\mathrm{E}_{\mathrm{TL}}\right)$

\section{CPC MULTILAYER THERMOMECHANICAL MEAN MODEL}

Consider a CPC multilayer composed of three physical layers (subscript $\mathrm{j}$ ): cardboard 1, plaster, cardboard 2. Each physical layer is discretized itself in "numerical" layers (subscript k). The total number of the numerical layers for the composite is denoted by $\mathrm{n}$. Each physical cardboard layer is assumed to be orthotropic while the plaster layer is assumed to be isotropic. The elasticity matrix of the constitutive equation of each numerical layer $\mathrm{k}(\mathrm{k}=1, \ldots, \mathrm{n})$ for the mean model is denoted by $\left[\underline{\mathrm{A}}^{k}\right]$ and is a matrix belonging to the set $\mathbb{M}_{5}^{+}(\mathbb{R})$ of all the positive-definite symmetric $(5 \times 5)$ real matrices. The multilayer system is defined in a cartesian coordinate axis (oxyz) with o in the middle of the composite.

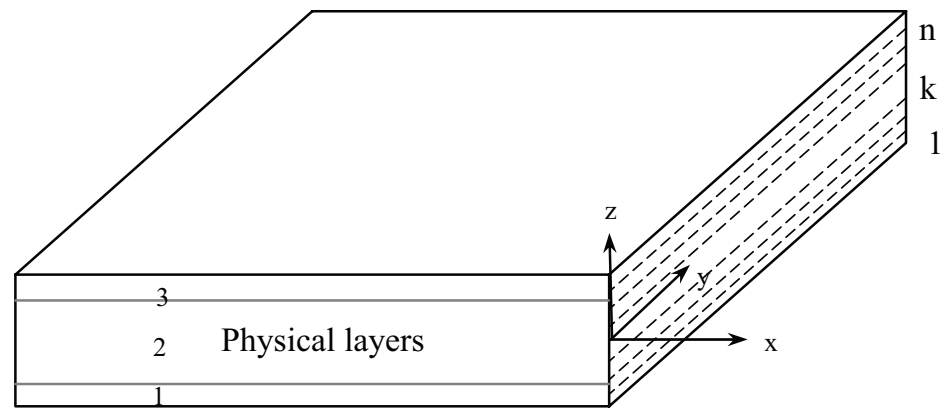

Numerical layers

FIGURE 5

SCHEMATIC REPRESENTATION OF THE CPC 


\section{CPC multilayer homogenization with damage}

The usual one dimensional homogenization through the thickness of the multilayer composite yields a matrix equation relating the membrane forces, $n_{i} i=\{1,2,6\}$, the bending moments $\mathrm{m}_{i}, i=\{1,2,6\}$ and the shear forces, $\mathfrak{n}_{i}, i=\{4,5\}$, with the membrane deformations $e_{j}^{m}, j=\{1,2,6\}$, the bending deformations $\kappa_{j}, j=\{1,2,6\}$ and the shear deformations $e_{j}, j=\{4,5\}$ :

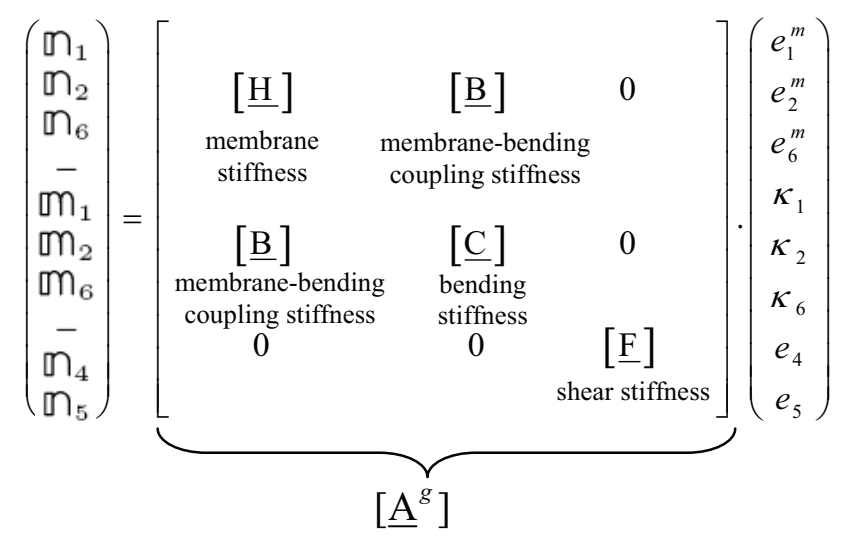

where

$$
\begin{aligned}
& {[\underline{H}]_{i j}=\sum_{k=1}^{n}\left(z_{k}-z_{k-1}\right) \cdot \underline{\tilde{A}}_{i j}^{k}(M, \theta) \quad i \text { and } j=1,2,6,} \\
& {[\underline{C}]_{i j}=1 / 3 \cdot \sum_{k=1}^{n}\left(z_{k}^{3}-z_{k-1}^{3}\right) \cdot \underline{\tilde{A}}_{i j}^{k}(M, \theta) \quad i \text { and } j=1,2,6,} \\
& {[\underline{B}]_{i j}=1 / 2 \cdot \sum_{k=1}^{n}\left(z_{k}^{2}-z_{k-1}^{2}\right) \cdot \underline{\tilde{A}}_{i j}^{k}(M, \theta) \quad i \text { and } j=1,2,6,} \\
& {[\underline{F}]=\sum_{k=1}^{n}\left(z_{k}-z_{k-1}\right)\left[\begin{array}{cc}
G_{T N}^{k} & 0 \\
0 & G_{N L}^{k}
\end{array}\right],}
\end{aligned}
$$

In which $\theta$ is the temperature and $\mathrm{M}=(\mathrm{x}, \mathrm{y}, \mathrm{z})$ a point in the $3 \mathrm{D}$ domain. The matrices $\left[\underline{\tilde{A}}^{k}(M, \theta)\right]$ are such that $\underline{\tilde{A}}_{i j}^{k}(M, \theta)=\left(1-\underline{d}_{i j}^{k}(M, \theta)\right) \underline{A}_{i j}^{k}(M, \theta)$ in which $\underline{A}_{i j}^{k}(M, \theta)$ and $\underline{d}_{i j}^{k}(M, \theta)$ correspond respectively to the stiffness and damage parameters of the layer k. Finally one has $\quad \underline{A}_{11}^{k}=E_{x} /\left(1-v_{x y} v_{y x}\right), \quad \underline{A}_{22}^{k}=E_{y} /\left(1-v_{x y} v_{y x}\right), \quad \underline{A}_{66}^{k}=G_{x y}, \quad \underline{A}_{12}^{k}=v_{x y} E_{y} /\left(1-v_{x y} v_{y x}\right)=\underline{A}_{21}^{k}$, $\underline{A}_{44}^{k}=G_{y z}^{k}, \underline{A}_{55}^{k}=G_{z x}^{k}$ and $\underline{A}_{45}^{k}=\underline{A}_{54}^{k}=\underline{A}_{26}^{k}=\underline{A}_{62}^{k}=\underline{A}_{16}^{k}=\underline{A}_{61}^{k}=0$.

\section{Heat transfer analysis}

Thermal diffusivity (Figure 6) of CPC plates is identified by an inverse problem performed with a developed finite elements code of heat transfer analysis and according to temperature-time tests carried out with the TLB. The CPC thermal conductivity is also identified by thermal experiments at the steady state performed with the TLB. The Heat transfer analysis through the thickness of the CPC multilayer (taking into account the identified parameters) allows the temperature in the middle of the different numerical layers of the CPC to be calculated as a function of the thermal load time (Figure 7). The 
mechanical characteristics of the CPC layers (Young's modulus) are modeled by an affine function $\theta \mapsto a \theta+b$ of the temperature. The parameters a and $\mathrm{b}$ have been identified with the thermo-mechanical response of the multilayer composite. This identification yields $\mathrm{a}=-3.7 \times 10^{6}$ and $\mathrm{b}=2.45 \times 10^{9}$ ).

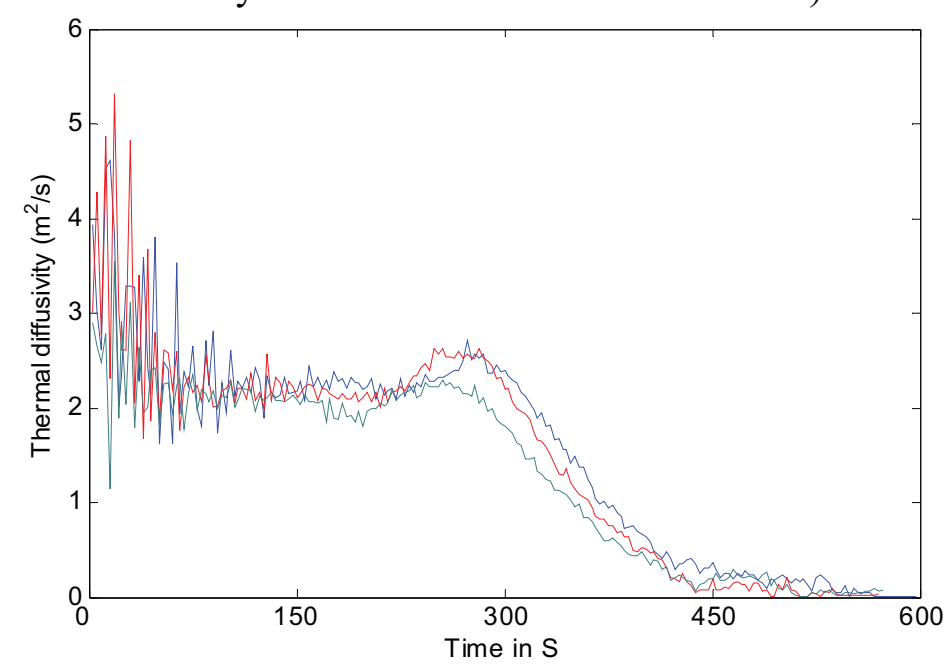

FIGURE 6

THERMAL DIFFUSIVITY OF THE CPC (VERTICAL AXIS IN $\mathrm{m}^{2} / \mathrm{s}$ ) AS A FUNCTION OF THE THERMAL LOAD TIME (HORIZONTAL AXIS IN SECOND)

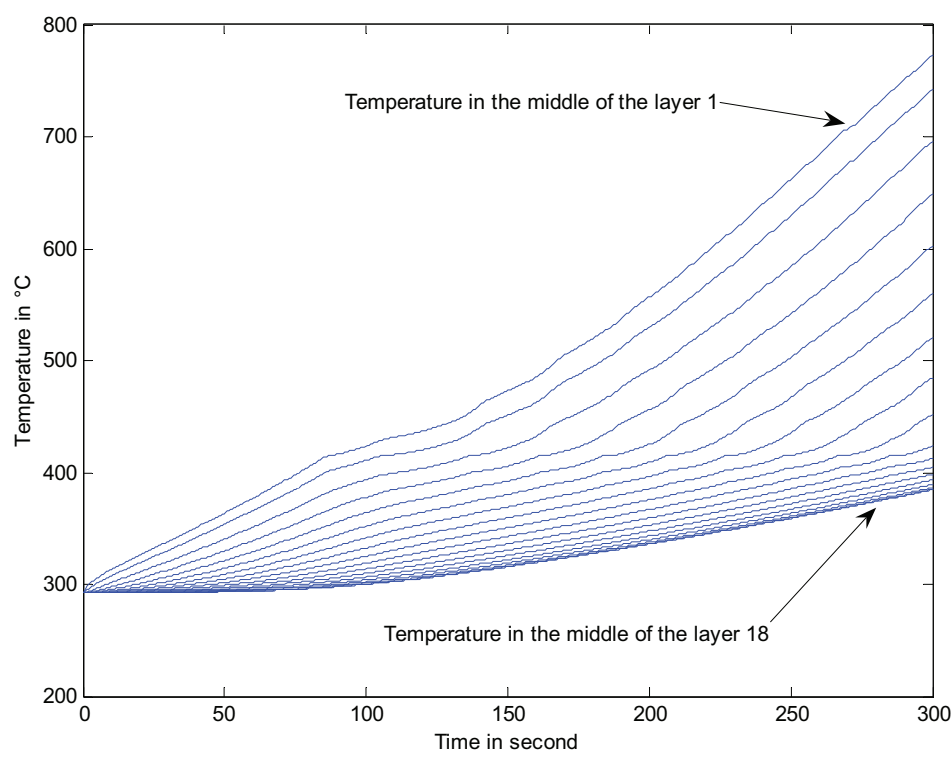

FIGURE 7

TEMPERATURE IN THE MIDDLE OF THE NUMERICAL LAYERS (VERTICAL AXIS IN ${ }^{\circ} \mathrm{C}$ ) AS A FUNCTION OF THE THERMAL LOAD TIME (HORIZONTAL AXIS IN SECOND)

\section{Damage model}

As a first approach, a cut-off model was adopted for the plaster layers. For each point of the modeled domain, the damage is equal to zero if the stress is less than the limit stress 
and equal to 1 otherwise. This first nonlinear approach used for modeling the global behavior of the CPC shows a good qualitative agreement with experimental results at $120^{\circ} \mathrm{C}$ and some differences at room temperature [6]. In order to improve the model prediction a brittle damage model for the plaster is implemented. The Najar's damage model [7] which is based on strain energy formulation has been chosen. According to it, the damage evolution law of each numerical layer of the plaster can be written as

$$
d^{k}= \begin{cases}d_{0}^{k} \exp \left(\omega^{k}\right) & \text { for } \alpha=0 \\ d_{0}^{k}\left(1+\alpha \omega^{k}\right)^{1 / \alpha} & \text { for } \alpha \neq 0\end{cases}
$$

In which the parameters $d_{0}^{k}, \alpha$ and $\omega^{k}$ depend on the temperature $\theta$ and the point M. In (2) $\omega^{k}=W_{\text {perf }}^{k} / W_{k}^{*}$, where $W_{\text {perf }}^{k}$ is the strain energy of the undamaged material for the layer $\mathrm{k}, W_{k}^{*}$ is the nominal damage energy for the layer $\mathrm{k}$ defined as the nominal capacity of the material to store energy in the form of internal structural damage, $d_{0}^{k}$ is the initial damage for the layer $\mathrm{k}$ and $\alpha$ is a model parameter.

\section{Nonlinear thermomechanical analysis of the CPC mean model}

A multilayer thin plate theory is used with the constitutive equation (1). A finite element code is developed for the nonlinear thermo-elastic model. The mechanical response of the CPC is calculated as a function of the external mechanical load corresponding to a four points bending test. The damage parameters are such that $\alpha_{20^{\circ} \mathrm{C}}=0.1,\left(d_{0}^{k}\right)_{20^{\circ} \mathrm{C}}=0.005,\left(w_{k}^{*}\right)_{20^{\circ} \mathrm{C}}=3.2 \mathrm{KJ} / \mathrm{m}^{3}$ for the temperature $\theta=20^{\circ} \mathrm{C}$ and $\alpha_{120^{\circ} \mathrm{C}}=0.8,\left(d_{0}^{k}\right)_{120^{\circ} \mathrm{C}}=0.005,\left(w_{k}^{*}\right)_{120^{\circ} \mathrm{C}}=2 \mathrm{KJ} / \mathrm{m}^{3}$ for the temperature $\theta=120^{\circ} \mathrm{C}$. Figure 8 and Figure 9 show the comparison of the experimental results with the numerical simulations for the applied mechanical load as a function of the transversal displacement at $20^{\circ} \mathrm{C}$ and $120^{\circ} \mathrm{C}$ respectively.

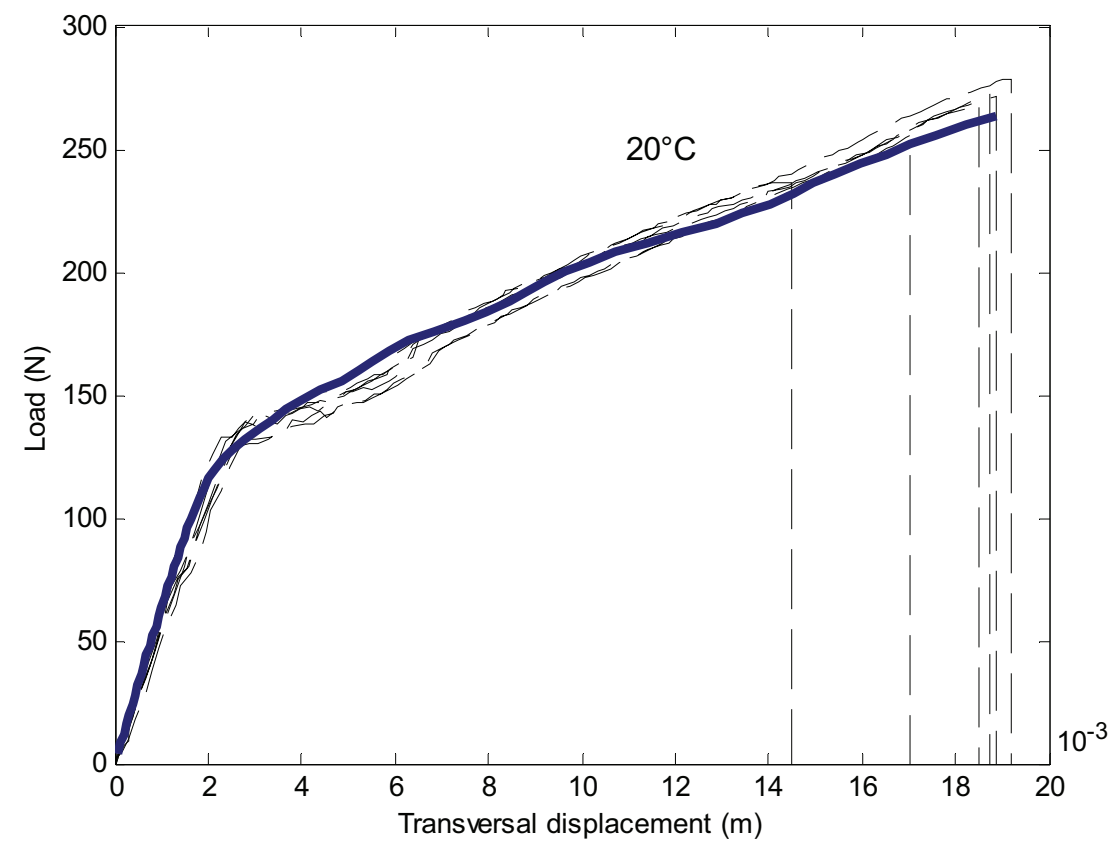




\section{FIGURE 8}

MECHANICAL APPLIED LOAD (VERTICAL AXIS IN N) AS A FUNCTION OF THE TRANSVERSAL DISPLACEMENT (HORIZONTAL AXIS IN METERS): EXPERIMENTS (DASHED THIN LINES) NUMERICAL SIMULATION OF THE NON LINEAR MEAN MODEL AT ROOM TEMPERATURE (THICK SOLID LINE)

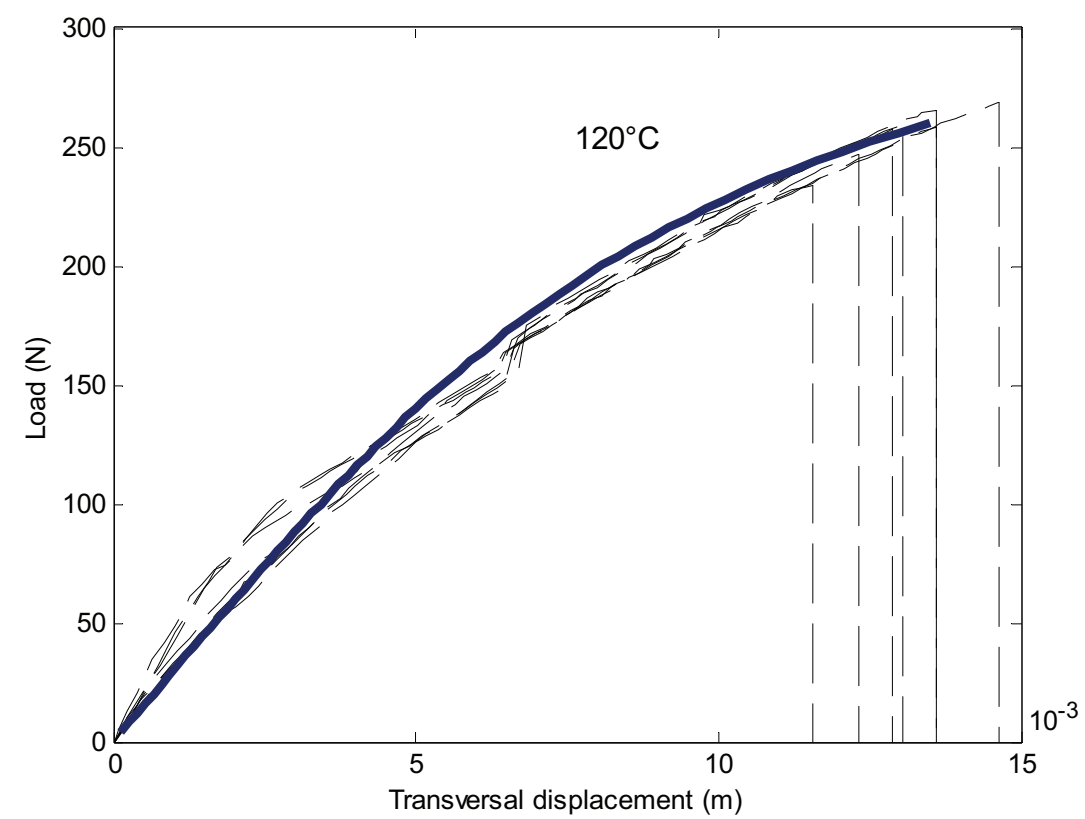

FIGURE 9

MECHANICAL APPLIED LOAD (VERTICAL AXIS IN N) AS A FUNCTION OF THE TRANSVERSAL DISPLACEMENT (HORIZONTAL AXIS IN METERS): EXPERIMENTS (DASHED THIN LINES), NUMERICAL SIMULATION OF THE NON LINEAR MEAN MODEL AT $120^{\circ} \mathrm{C}$ (THICK SOLID LINE)

\section{CPC MULTILAYER PROBABILISTIC MODEL}

We now consider data and model uncertainties in the physical layers (subscript $\mathrm{j}$ ). We propose to apply the nonparametric probabilistic approach [9] to the nonlinear multilayer mean model for taking into account these uncertainties. According to this theory, a random model $\left[\mathbf{A}^{j}\right]$ of the whole mean stiffness matrix $\left[\underline{A}^{j}\right]$ is constructed rather than constructing a probabilistic model of each uncertain parameter (parametric probabilistic approach).

\section{CPC random global stiffness matrix}

Each stiffness random matrix $\left[\mathbf{A}^{j}\right]$ is with value in $\mathbb{M}_{5}^{+}(\mathbb{R})$ (plate model). The probability density function of this matrix is constructed following the procedure given in the next section. An homogenization through the thickness of the CPC (as for the mean model) is applied to the random multilayer composite and yields the random matrix $\left[\mathbf{A}^{g}\right]$ of the random homogenized constitutive equation

$$
\left[\mathbf{A}^{g}\right]=\operatorname{hom}\left(\left[\mathbf{A}^{1}\right], \ldots,\left[\mathbf{A}^{J}\right]\right)
$$




\section{Probability density function of the random stiffness matrix of the layer $j$}

The probability density function of the matrix $\left[\mathbf{A}^{j}\right]$ is constructed using the maximum entropy principle [10]. The maximum entropy principle allows the probability density function of a random variable to be constructed in maximizing the entropy function under constraints defined by the available information. The available information is defined as follows:

- The matrix $\left[\mathbf{A}^{j}\right]$ is symmetric positive-definite,

- The mean value is given $E\left\{\left[\mathbf{A}^{j}\right]\right\}=\left[\underline{\mathrm{A}}^{j}\right]$ in which $E\{$.$\} denotes the mathematical$ expectation.

- $E\left\{\left\|\left[\mathbf{A}^{j}\right]^{-1}\right\|_{F}^{2}\right\}<+\infty$, where $\|[\mathbf{A}]\|_{F}=\left(\operatorname{tr}\left\{[\mathbf{A}][\mathbf{A}]^{T}\right\}\right)^{1 / 2}$ is the Frobenius norm.

The last constraint insures the existence of a second-order solution of the stochastic problem. The random matrix $\left[\mathbf{A}^{j}\right]$ is written as:

$$
\left[\mathbf{A}^{j}\right]=\left[\underline{\mathrm{L}}_{A^{j}}\right]^{T}\left[\mathbf{G}_{A^{j}}\right]\left[\underline{\mathrm{L}}_{A^{j}}\right]
$$

where $\left[\underline{\mathrm{L}}_{A^{j}}\right]$ is a $(5 \times 5)$ real upper triangular matrix such that $\left[\underline{\mathrm{A}}^{j}\right]=\left[\underline{\mathrm{L}}_{A^{j}}\right]^{T}\left[\underline{\mathrm{L}}_{A^{j}}\right]$. The probability distribution function of the random matrix $\left[\mathbf{G}_{A^{j}}\right]$ is defined with value in $\mathbb{M}_{5}^{+}(\mathbb{R})$ by the probability density function $\left[\mathrm{G}_{A^{j}}\right] \mapsto p_{\left[\mathrm{G}_{A^{j}}\right]}\left(\left[\mathrm{G}_{A^{j}}\right]\right)$ from $\mathbb{M}_{5}^{+}(\mathbb{R})$ in $\mathbb{R}^{+}$ with regards to the measure $\tilde{d} \mathrm{G}_{A^{j}}$ such that $\tilde{d} \mathrm{G}_{A^{j}}=2^{n(n-1) / 4} \prod_{1 \leq i \leq k \leq n} d\left[\mathrm{G}_{A^{j}}\right]_{i k}$ and such that

$$
p_{\left[\mathbf{G}_{A^{j}}\right]}\left(\left[\mathrm{G}_{A^{j}}\right]\right)=\mathbf{1}_{\mathbb{M}_{n}^{+}(\mathbb{R})}\left(\left[\mathrm{G}_{A^{j}}\right]\right) \times c_{\mathbf{G}_{A^{j}}} \times\left(\operatorname{det}\left[\mathrm{G}_{A^{j}}\right]\right)^{\frac{\left(1-\delta_{j}^{2}\right)}{\delta_{j}^{2}}} \times \exp \left(-\frac{3}{\delta_{j}^{2}} \operatorname{tr}\left[\mathrm{G}_{A^{j}}\right]\right)
$$

in which normalization positive constant $c_{\mathbf{G}_{A^{j}}}$ is written as

$$
c_{\mathbf{G}_{A^{j}}}=\frac{(2 \pi)^{-5}\left(\frac{3}{\delta_{j}^{2}}\right)^{15\left(\delta_{j}^{2}\right)^{-1}}}{\left\{\prod_{l=1}^{n} \Gamma\left(\frac{3}{\delta_{j}^{2}}+\frac{1-l}{2}\right)\right\}}
$$

where $\Gamma(z)$ is the gamma function defined for $z>0$ by $\Gamma(z)=\int_{0}^{+\infty} t^{z-1} e^{-t} d t$. The parameter $\delta_{j}$ allows the probability model dispersion of the random matrix $\left[\mathbf{G}_{A^{j}}\right]$ to be controlled (and then the dispersion of the random matrix $\left[\mathbf{A}^{j}\right]$ to be controlled).

$$
\delta_{j}=\left\{E\left\{\left\|\left[\mathbf{G}_{A^{j}}\right]-\left[\underline{\mathrm{G}}_{A^{j}}\right]\right\|_{F}^{2}\right\} /\left\|\left[\mathrm{G}_{A^{j}}\right]\right\|_{F}^{2}\right\}^{1 / 2}
$$

The parameter $\delta_{j}$ is independent of the random matrix dimension and must be such that

$$
0<\delta<\sqrt{(0.6)}
$$

For the Monte-Carlo method, the realizations of the random matrices $\left[\mathbf{G}_{A^{j}}\right]$ are constructed using the following algebraic representation: 


$$
\left[\mathbf{G}_{A^{j}}\right]=\left[\mathbf{L}_{j}\right]^{T}\left[\mathbf{L}_{j}\right]
$$

where $\left[\mathbf{L}_{j}\right]$ is an upper random triangular matrix such that :

- Random variables $\left\{\left[\mathbf{L}_{j}\right]_{k k^{\prime}}, k \leq k^{\prime}\right\}$ are independent,

- For $k \leq k^{\prime}$, the random variable $\left[\mathbf{L}_{j}\right]_{k k^{\prime}}$, is such $\left[\mathbf{L}_{j}\right]_{k k^{\prime}}=\sigma_{j} Y_{k k^{\prime}}$, in which $\sigma_{j}=\delta_{j} / \sqrt{6}$ and $Y_{k k^{\prime}}$ is a normalized Gaussian random variable,

- For $k=k^{\prime},\left[\mathbf{L}_{j}\right]_{k k}=\sigma_{j} \sqrt{2 V_{k j}}$ where $V_{k j}$ is a gamma random variable which probability density function written as

$$
p_{V_{j}}(v)=\mathbf{1}_{\mathbb{R}^{+}}(v) \frac{1}{\Gamma\left(3 / \delta_{j}^{2}+(1-k) / 2\right)} v^{\left(\frac{3}{\delta_{j}^{2}+\frac{1-k}{2}}\right)} e^{-v}
$$

\section{Finite elements discretization of the BVP}

The nonlinear stochastic boundary value problem is approximated by the usual finite elements method (also called stochastic finite elements method).

\section{Stochastic solver}

The numerical Monte-Carlo method is used as a stochastic solver for the of the random nonlinear equation. Let $U$ be the random transversal displacement of the CPC pate at a fixed point. The confidence region with regards to a given probability level is defined by the upper and the lower envelopes ( $u^{+}$and $u^{-}$respectively) such as

$$
\operatorname{Prob}\left(u^{-}<U \leq u^{+}\right)=P_{c}
$$

\section{Stochastic convergence}

The convergence with respect to the number $n_{s}$ of realizations $r_{1}, \ldots, r_{n_{s}}$ used in the Monte Carlo calculation is studied by the function

$$
\operatorname{conv}\left(n_{s}\right)=\left\{\frac{1}{n_{s}} \sum_{k=1}^{n_{s}} U\left(r_{k}\right)^{2}\right\}^{1 / 2}
$$

\section{Prediction of the probabilistic model and experimental comparison}

We consider the BVP corresponding to a four points bending test and discretized by the stochastic finite elements method. We are interested in to the random response $U$ as a function of the applied load. Two cases are considered, the first one corresponds to $20^{\circ} \mathrm{C}$ and the second one corresponds to $120^{\circ} \mathrm{C}$. The dispersion parameters of the physical layers have been identified with the experimental data using the random response $U$ and yields

- At $20^{\circ} \mathrm{C},\left(\delta_{\text {plaster }}\right)_{20^{\circ} \mathrm{C}}=0.15$ and $\left(\delta_{\text {cardboard }}\right)_{20^{\circ} \mathrm{C}}=0.08$. 
- At $120^{\circ} \mathrm{C},\left(\delta_{\text {plaster }}\right)_{120^{\circ} \mathrm{C}}=0.18$ and $\left(\delta_{\text {cardboard }}\right)_{120^{\circ} \mathrm{C}}=0.09$.

For each temperature case, the Monte Carlo numerical simulation is carried out for $n_{s}$ simulations with $\left(n_{s}\right)_{20^{\circ} \mathrm{C}}=350$ and $\left(n_{s}\right)_{120^{\circ} \mathrm{C}}=700$. Figure 10 and Figure 11 are related to the convergence function (12) at $20^{\circ} \mathrm{C}$ and at $120^{\circ} \mathrm{C}$ respectively. Figure 12 and Figure 13 display the comparisons of experiments with the confidence regions with $P_{c}=0.98$ at $20^{\circ} \mathrm{C}$ and $120^{\circ} \mathrm{C}$ respectively.

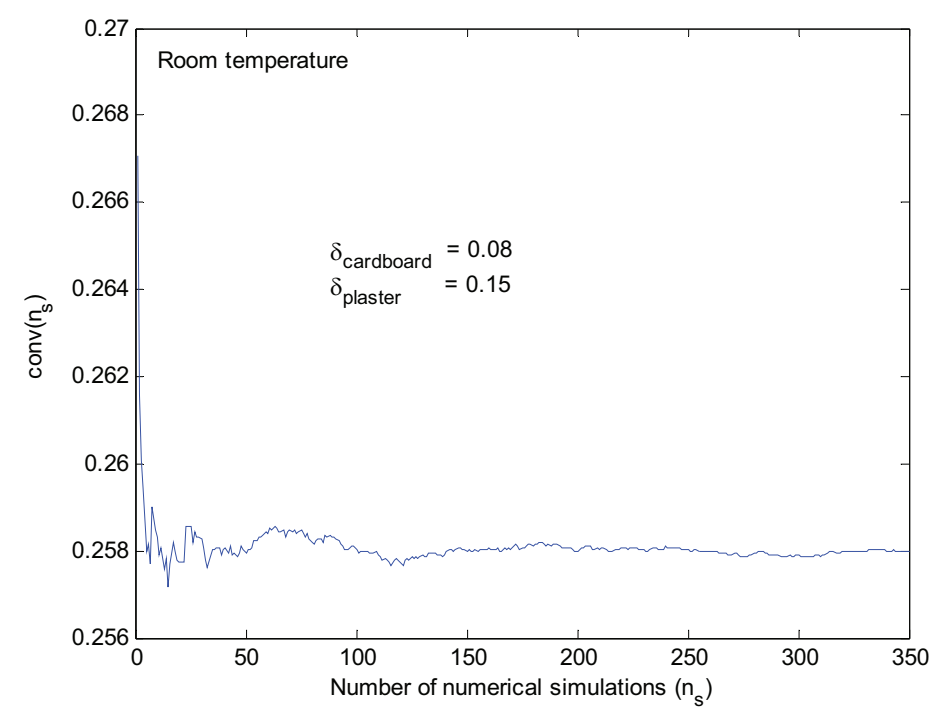

FIGURE 10

CONVERGENCE FUNCTION (VERTICAL AXIS) AS A FUNCTION OF THE NUMBER OF SIMULATIONS AT ROOM TEMPERATURE

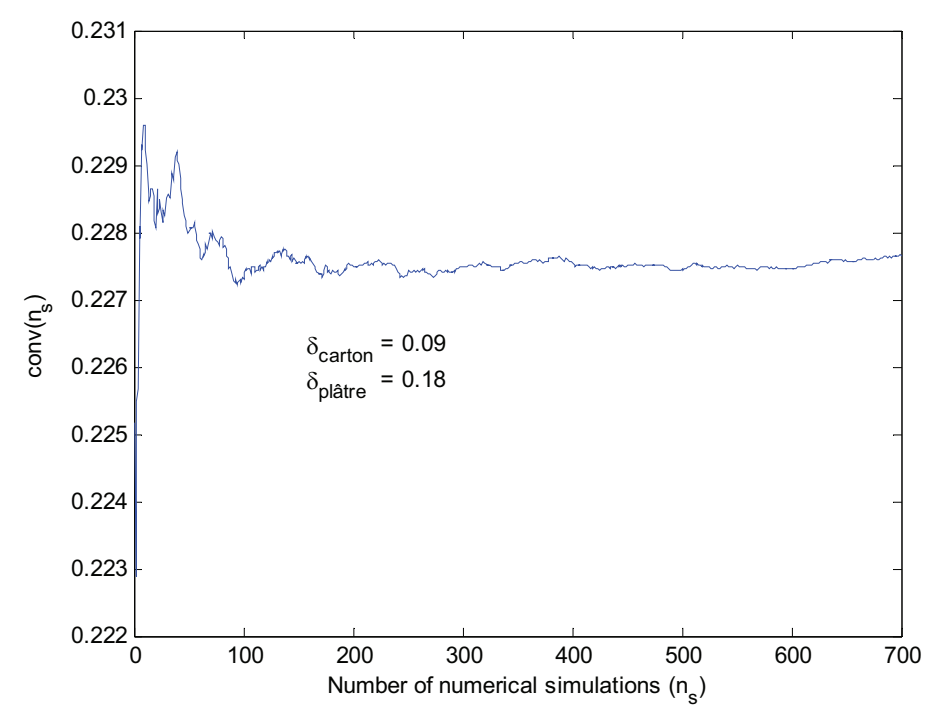

FIGURE 11

CONVERGENCE FUNCTION (VERTICAL AXIS) AS A FUNCTION OF THE NUMBER $\mathrm{N}_{\mathrm{S}}$ OF REALIZATIONS AT $120^{\circ} \mathrm{C}$ 


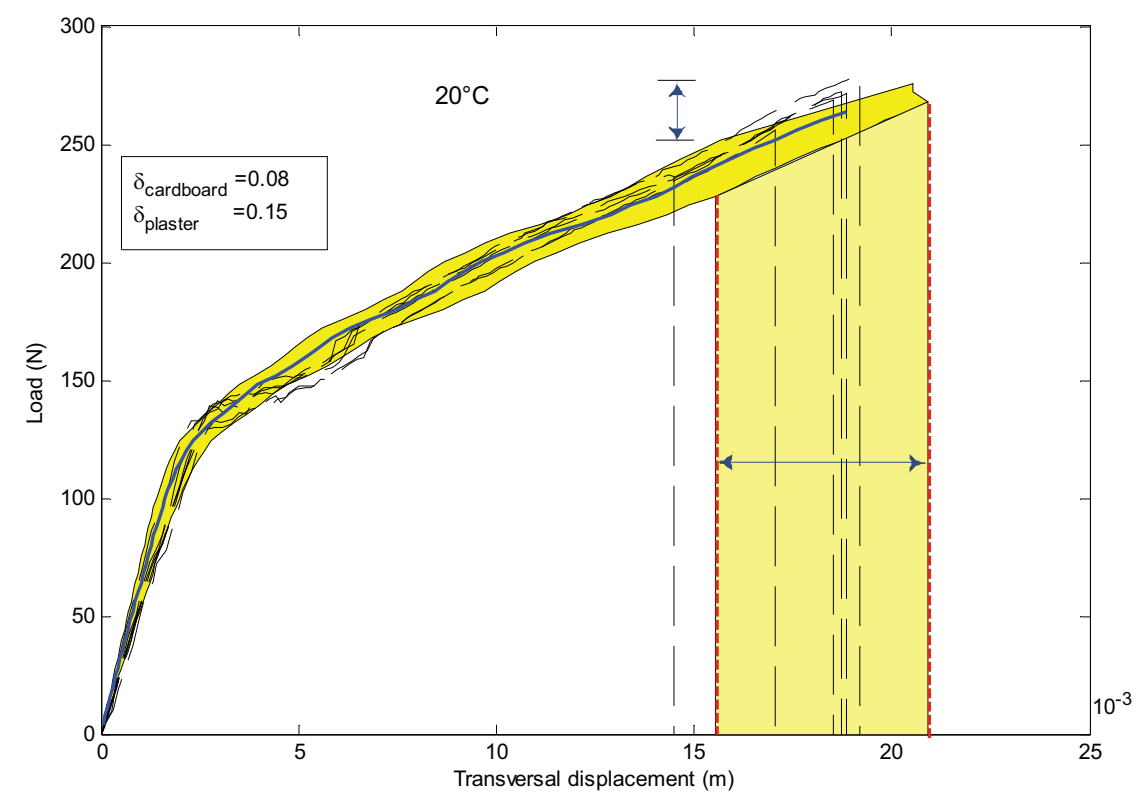

FIGURE 12

RESULTS FOR $20^{\circ} \mathrm{C}$ : MECHANICAL APPLIED LOAD (VERTICAL AXIS IN N) AS A FUNCTION OF THE TRANSVERSAL DISPLACEMENT (HORIZONTAL AXIS IN METERS): EXPERIMENTS (DASHED THIN LINES), NUMERICAL SIMULATION WITH THE MEAN MODEL (THICK SOLID LINE), CONFIDENCE REGION WITH THE STOCHASTIC MODEL (GREY REGION)

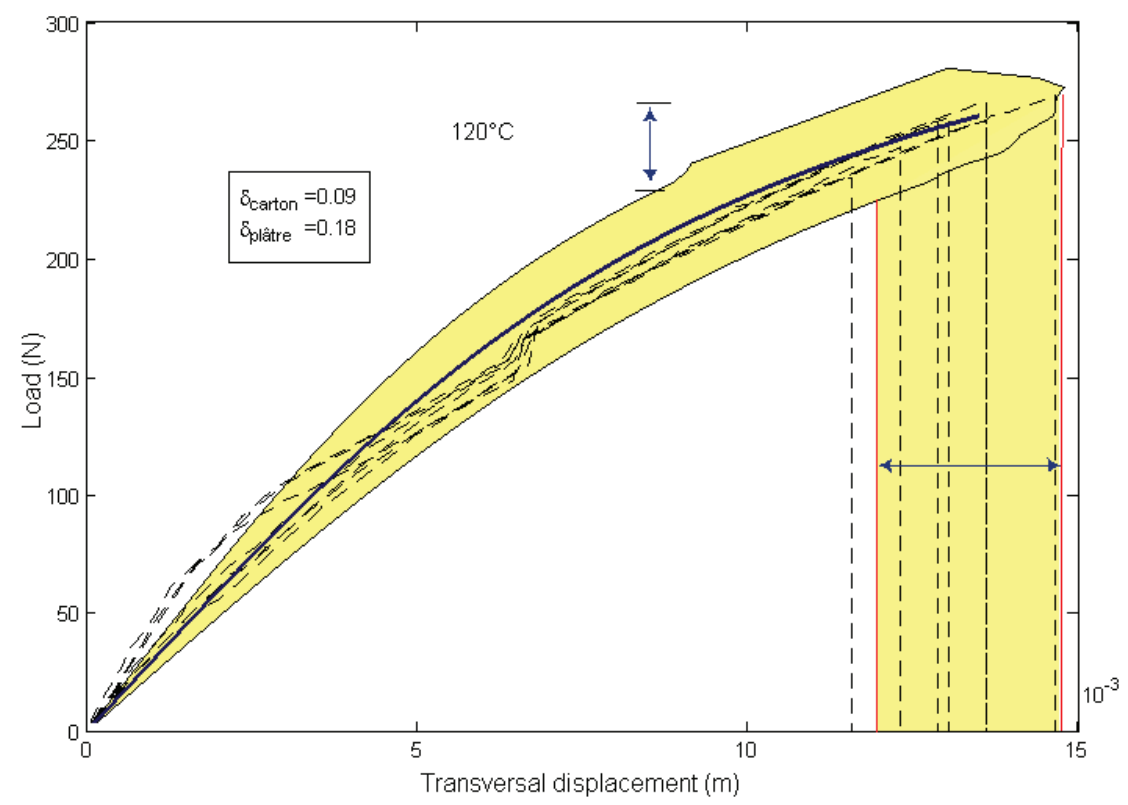

\section{FIGURE 13}

RESULTS FOR $120^{\circ} \mathrm{C}$ : MECHANICAL APPLIED LOAD (VERTICAL AXIS IN N) AS A FUNCTION OF THE TRANSVERSAL DISPLACEMENT (HORIZONTAL AXIS IN METERS): EXPERIMENTS (DASHED THIN LINES) NUMERICAL SIMULATION WITH THE MEAN MODEL (THICK SOLID LINE) CONFIDENCE REGION WITH THE STOCHASTIC MODEL(GREY REGION) 


\section{CONCLUSION}

A deterministic and a probabilistic nonlinear thermo-mechanical with experiments has been presented for studying a cardboard-plaster-cardboard multiplayer plate. The dispersion parameters of the cardboard and the plaster have been identified for two temperature according to the ISO834 thermal load curve. The proposed model is validated by experiments. The next step of this work is to construct a continuous representation of these parameters as a function of temperature. We the get a complete model in order to analyze the thermo-mechanical behavior of a light lined partition submitted to fire load and taking into account the random uncertainties.

\section{REFERENCES}

[1] DTU 25-41, French standards, "Building works-Gypsum plasterboard works-Gypsum wallboards", Part 1: Technical specifications, AFNOR 1993.

[2] European prestandard, Part 2-2: Actions on structures exposed to fire, "Eurocode1: Basis of design and actions on structures", pp 20-23.

[3] Benouis, A, "Comportement mécanique des ouvrages en plaque de plâtre sur ossature métallique" Doctorate thesis Ecole Nationale des Ponts et Chaussées (ENPC), September 1995.

[4] Axenenko, O, Thrope, G, " The modelling of dehydration and stress analysis of gypsum plasterboards exposed to fire ", computational materials science 6, 1996. pp281-294.

[5] Fromy, Ph, Curtat, M, R, "Heat transfer in fire resistance furnaces piloted with thermocouples or plate thermometers", Fire Safety Science Proceedings of the sixth international symposium, July 1999, pp 531-542.

[6] Decolon, C, Structures composites, calcul des plaques et poutres multicouches. Hermes, Paris, 2000.

[7] Najar, J, "Continuous damage of brittle solids", Continuum damage mechanics, theory and applications. Springer - Verlag - Wien - New York. CISM, ITALY, 1987,.pp 233-294

[8] Sakji, S, Soize, C, Heck J-V, "Thermo-mechanical model of a cardboard-plaster-cardboard composite plate submitted to fire load and experiments", Materials characterization conference, November 2005.

[9] Soize, C, "A nonparametric model of random uncertainties for reduced matrix models in structural dynamics", Journal of Probabilistic engineering mechanics, 15, 2000, pp 277-294.

[10] Soize, C, "Maximum entropy approach for modeling random uncertainties in transient elastodynamics", Journal of the Acoustics Society of America, May 2001, pp 1979-1996. 